Pacific Journal of Mathematic

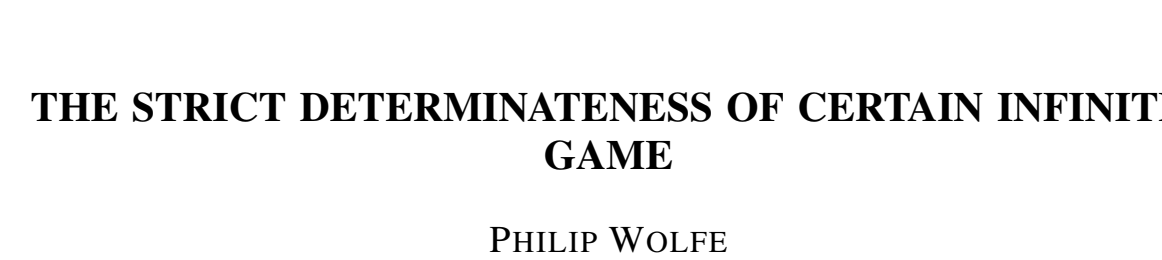




\section{THE STRICT DETERMINATENESS OF CERTAIN INFINITE GAMES}

\section{PhILIP WOLFE}

1. Introduction. Gale and Stewart [1] have discussed an infinite two-person game in extensive form which is the generalization of a game as defined by Kuhn [3] obtained by deleting the requirement of finiteness of the game tree and regarding as plays all unicursal paths of maximal length originating in the distinguished vertex $x_{0}$. In a winlose game the set $S$ of all plays is divided into two sets $S_{I}$ and $S_{I I}$ such that player $I$ wins the play $s$ if $s \in S_{I}$ and player $I I$ wins it if $s \in S_{I I}$. Gale and Stewart have shown that a two-person infinite win-lose game of perfect information with no chance moves (called a GS game here) is strictly determined if $S_{I}$ belongs to the smallest Boolean algebra containing the open sets of a certain topology for $S$. Here we answer affirmatively the question posed by them: Is a GS game strictly determined if $S_{I}$ is a $G_{\delta}$ (or, equivalently, an $F_{\sigma}$ )? The notation and results of [1] are used throughout, as well as the partial ordering of $X$ given by: $x>y$ if $f^{n}(x)=y$ for some $n \geqslant 1$.

2. Alternative description of $S_{I}$. Let $\Gamma$ be the game $\left(x_{0}, X_{I}, X_{I I}\right.$ $\left.X, f, S, S_{1}, S_{I I}\right)$, where

$$
S_{I}=\bigcap_{n=1}^{\infty} E_{n}
$$

$E_{1} \supseteq E_{2} \supseteq \cdots$, and $E_{n}$ is open. Following [3], let the rank $r k(x)$, for $x \in X$, be the unique $k$ such that $f^{k}(x)=x_{0}$. As in [1], $\mathfrak{U}(x)$ is the set of all plays passing through $x$ (the topology for $S$ is that in which $\mathfrak{U}(x)$ is a neighborhood of each play in it). Then for each $n$,

$$
E_{n}=\bigcup\left\{\mathfrak{u}(y): \mathfrak{u}(y) \subseteq E_{n}\right\} ;
$$

and since for any $y \in X$ we have

$$
\mathfrak{U}(y)=\bigcup\{\mathfrak{U}(z): f(z)=y\},
$$

with

$$
r k(z)=1+r k(y)
$$

Received October 3, 1953. The work in this paper was done during the author's tenure of an Atomic Energy Commission Predoctoral Fellowship. 
there exists for each $n$ a subset $Y_{n}$ of $X$ such that $r k(y)>n$ for all $y \in Y_{n}$ and

$$
E_{n}=\bigcup\left\{\mathfrak{l}(y): y \in Y_{n}\right\} .
$$

Furthermore, since of any two neighborhoods having a non-void intersection, one is contained in the other, each $Y_{n}$ may be chosen so that $\mathfrak{u}(y), \mathfrak{u}\left(y^{\prime}\right)$ are disjoint for different $y, y^{\prime}$ in $Y_{n}$.

Since $s \in S_{1}$ if and only if $s \in E_{n}$ for an infinite number of values of $n$, we have: $s \in S_{I}$ if and only if for infinitely many $n$ there exists $i$ (dependent on $n$ ) such that $s(i) \in Y_{n}$. Thus, since on the one hand $i=r k(s(i))>n$, and on the other for any $n$ there is at most one $i$ such that $s(i) \in Y_{n}$, letting

$$
Y=\bigcup_{n=1}^{\infty} Y_{n}
$$

we have: $s \in S_{I}$ if and only if $s(i) \in Y$ for infinitely many $i$.

\section{Lemmas.}

LEMMA 1. If $\Gamma$ is a GS game with

$$
\sum_{I I}^{W}(\Gamma)=\Lambda
$$

and

$$
T=S-\bigcup\left\{\mathfrak{l}(x): \sum_{I I}^{W}\left(\Gamma_{x}\right) \neq \mathcal{A}\right\},
$$

then

$$
I_{T}^{\prime}=\left(x_{0}, X_{I}^{T}, X_{I I}^{T}, X^{T}, f^{T}, T, S_{I}^{T}, S_{I I}^{T}\right)
$$

is a subgame of $\Gamma$,

$$
\sum_{l}^{W}\left(\Gamma_{T}\right) \rightleftharpoons \Lambda
$$

implies

$$
\sum_{I}^{W}(I) \rightleftharpoons \Lambda,
$$

and

$$
\sum_{I I}^{W}\left(\left(I_{T}\right)_{x}\right)=\Lambda
$$

for all $x \in X^{T}$.

Proof. Since $T$ is a closed nonempty subset of $S, \Gamma_{T}$ is a subgame of $\Gamma$ by Theorem 5 of [1]. The second statement follows from assertion $B[1$, p. 260]. Finally suppose that

$$
\sum_{I I}^{W}\left(\left(\Gamma_{T}\right)_{x}\right) \rightleftharpoons A
$$

for some $x \in X^{T}$. Letting, in assertion A [1, p. 260],

$$
F=\mathfrak{u}(x) \cap T,
$$


and noting that $F$ is closed and nonempty and that

$$
\left(I^{\prime}\right)_{r}=\left(I^{\prime}\right)_{F^{\prime}},
$$

we have

$$
\sum_{I I}^{W}\left(I^{\prime}\right) \neq 1,
$$

which is impossible in view of the construction of $T$.

We assume hereafter that $\Gamma$ is a GS game with $S_{I}$ described in terms of $Y \subseteq X$ as in $\S 2$, and that

$$
\sum_{I I}^{W}\left(I^{\prime}\right)=\Lambda,
$$

whence

$$
\sum_{I I}^{W^{T}}\left(I_{T}^{\prime}\right)=\Lambda
$$

by Lemma 1 . The strict determinateness of $\Gamma$ will follow from Lemma 1 and the fact that

$$
\sum_{I}^{W}\left(\Gamma_{T}\right) \neq \Lambda
$$

proved in $\S 4$.

Lemma 2. For $x \in X^{r}$, we have

$$
s \in S_{I}^{r \cdot x}
$$

if and only if

$$
s \in S^{T \cdot r} \quad \text { and } \quad s(i) \in Y
$$

for infinitely many $i$.

Lemma 3. For $x \in X^{T}$ there exists

$$
\sigma_{x} \in \sum_{I}\left(\left(\Gamma_{T}\right)_{x}\right)
$$

such that for any

$$
\tau \in \Sigma_{H I}\left(\left(I^{\prime}\right)_{x}\right)
$$

we have

$$
\left\langle\sigma_{x}, \tau\right\rangle(i) \in Y
$$

for some $i>r k(x)$.

Proof. Let $Y_{x}$ be the set of all

$$
y \in Y \cap X^{p}
$$

such that $y>x$ and no members of $Y$ fall between $x$ and $y$. Let $\Gamma^{\prime}$ be the game 


$$
\left(x_{0}, X_{I}^{T x}, X_{I I}^{T x}, X^{T x}, f^{T x x}, S^{T x}, S_{I}^{\prime}, S_{I I}^{\prime}\right)
$$

where

$$
S_{I}^{\prime}=S^{T r x} \cap \bigcup\left\{\Pi(y): y \in Y_{x}\right\}
$$

and

$$
S_{I I}^{\prime}=S^{T x}-S_{I}^{\prime}
$$

(that is, the game in which $I$ wins if the play passes through any member of $Y$ following $x$ ). Noting that

$$
S_{I}^{T x} \subseteq S_{1}^{\prime}
$$

we have

$$
S_{I I}^{\prime} \subseteq S_{I i}^{T n}
$$

and hence

$$
\sum_{H I}^{W}\left(I^{\prime \prime}\right)=\Lambda
$$

But $S_{I}^{\prime}$ is open in $S^{T x}$ and so $I^{\prime \prime}$ is strictly determined by Corollary 10 of [1], whence there exists

$$
\sigma_{x} \in \sum_{I}^{W}\left(\Gamma^{\prime}\right)
$$

which satisfies the conclusion of the lemma.

\section{Winning $I_{T}^{\prime}$. Let}

$$
Y^{\prime}=\left(Y \cap X^{T}\right) \cup\left\{x_{0}\right\} .
$$

For each $x \in Y^{\prime}$ let $\sigma_{x}$ be as given by Lemma 3 , and let $\sigma_{x}^{\prime}$ be the restriction of $\sigma_{x}$ to the set of all $z$ in $X^{T}$ such that $x \leqslant z$ and that there exists no $y$ in $Y^{\prime}$ with $x<y \leqslant z$. We show that the domains of the $\sigma_{x}^{\prime}$ cover $X^{r}$ and are disjoint: First, if $x_{0} \in X_{I}^{T}$, then $x_{0}$ belongs to the domain of $\sigma_{x_{0}}$. For

$$
z \in X_{I}^{T}-\left\{x_{0}\right\}
$$

let

$$
x=\max \left\{z^{\prime}: z^{\prime} \in Y^{\prime} \& z^{\prime}<z\right\} .
$$

Then $x \in Y^{\prime}$ and $z$ belongs to the domain of $\sigma_{x}^{\prime}$; thus the domains of the $\sigma_{x}^{\prime}$ cover $X_{I}^{r^{\prime}}$. Now suppose that $x_{1}, x_{2} \in Y^{\prime}, x_{1} \neq x_{2}$, and that there exists $x_{3}$ common to the domains of $\sigma_{x_{1}}^{\prime}$ and $\sigma_{x_{2}}^{\prime}$; then $x_{1} \leqslant x_{3}$ and $x_{2} \leqslant x_{3}$, so that either $x_{1}<x_{2} \leqslant x_{3}$ or $x_{2}<x_{1} \leqslant x_{3}$, which is impossible in view of the restriction imposed upon $\sigma_{,}$in obtaining $\sigma_{x}^{\prime}$.

Since the domains of the $\sigma_{x}^{\prime}$ cover $X_{1}^{r}$ and are disjoint, they have 
a common extension $\sigma^{*}$, which necessarily maps the elements of $X_{I}^{T}$ on their immediate successors, and thus belongs to $\sum_{l}\left(I_{T}{ }_{T}\right)$.

We show that $\sigma^{*}$ wins $\Gamma_{T}$. Let

$$
\tau \in \sum_{I I}\left(\Gamma_{T}\right) .
$$

For this $\tau$ and any $x$ in $Y^{\prime}$, let $i(x)$ be the least $i$ such that $\left\langle\sigma_{x}, \tau\right\rangle(i) \in Y^{\prime}$, whose existence is given by Lemma 3 . Define $\left\{x_{n}\right\}$ inductively by

$$
x_{n+1}=\left\langle\sigma^{*}, \tau\right\rangle\left(i\left(x_{n}\right)\right) \quad n=0,1, \cdots
$$

$\left(x_{0}\right.$ is the distinguished vertex). Since

$$
r k\left(x_{n+1}\right)=i\left(x_{n}\right)>r k\left(x_{n}\right),
$$

and $x_{n}, x_{n+1}$ are on a common path, we have $x_{n+1}>x_{n}$ for all $n$, and so if $x_{n} \in Y^{\prime}$ then

$$
x_{n+1}=\left\langle\sigma^{*}, \tau\right\rangle\left(i\left(x_{n}\right)\right)=\left\langle\sigma_{x_{n}}, \tau_{x_{n}}\right\rangle\left(i\left(x_{n}\right)\right) \in Y^{\prime},
$$

where

$$
\tau_{x_{n}} \in \sum_{I I}\left(\left(\Gamma_{T}\right)_{x_{n}}\right)
$$

is the restriction of $\tau$ to $X_{I I}^{\tau \cdot x_{n}}$. Thus by induction $x_{n} \in Y^{\prime}$ for all $n$, and hence

$$
\left\langle\sigma^{*}, \tau\right\rangle(i) \in Y
$$

for infinitely many values of $i$, so that

$$
\left\langle\sigma^{*}, \tau\right\rangle \in S_{j}^{\prime \prime} \text {. }
$$

Since $\tau$ is arbitrary,

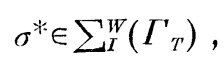

so that by Lemma 1 , we have

$$
\sum_{I}^{W}(\Gamma) \rightleftharpoons \Lambda
$$

As this is the consequence of the sole fact that

$$
\sum_{I I}^{W}(\Gamma)=\Lambda
$$

$\Gamma$ is strictly determined.

Reversing the roles of the players in the above gives the result that a GS game is strictly determined if $S_{I}$ is an $F_{\sigma}$.

The strict determinateness of a two-person zero-sum game with $G$ payoff having chance moves can be shown. The proof is more complicated, but uses the same ideas [4].

5. An application. Let

$$
I^{\prime}=\left(x_{1}, X_{1}, X_{I l}, X, f, S, \phi\right)
$$


be a zero-sum two-person infinite game of perfect information with no chance moves having payoff $\Phi$ such that there exists a real function $h$ on $X(|h(x)|<K<\infty)$ with

$$
\Phi(s)=\limsup _{i \rightarrow \infty} h(s(i)) \text { for all } s \in S .
$$

$\Gamma$ is the result of an attempt to reduce the following situation to a game: The tree $K$ of a GS game and a function $h$ as above are given; the two players make choices in $K$ in the belief that every play will terminate in some unknown, but distant, vertex $x$, at which time player $I$ will receive the amount $h(x)$ from player $I I$. A payoff function $\Phi$ is sought such that $\Phi(s)(-\Phi(s))$ expresses the utility to player $I(I I)$ of a play $s$ in $K$.

The payoff $\Phi$ defined above arises from ascription to players $I$ and II respectively of "optimistic" and "pessimistic" behaviors in this way: Player $I$ assumes that the play $s$ will terminate in some "distant" vertex $s(i)$ at which $h$ assumes nearly its supremum on all "distant" vertices of $s$; he thus makes his choices so as to maximize the expression

$$
\limsup _{i \rightarrow \infty} h(s(i))=\Phi(s) ;
$$

and player II supposes that $s$ will terminate in some "distant" vertex at which his gain $-h(s(i))$ assumes nearly its infimum for all such vertices, and thus seeks to maximize

$$
\liminf _{i \rightarrow \infty}-h(s(i))=-\Phi(s),
$$

that is, to minimize $\Phi$. The derived game is thus zero-sum. Ascription, however, of such "optimistic" or "pessimistic" payoffs to both players yields, in general, a non-zero sum game.

We show now that the game $\Gamma$ of this section is strictly determined, using the method of Theorem 15 of [1] which asserts the strict determinateness of $I$ for the more special case of continuous $\Phi$. (Gillette [2] has shown the strict determinateness of an infinite game of perfect information with chance moves which consists in repeated play from a finite set of finite games and has payoff

$$
\limsup _{n \rightarrow \infty} \frac{1}{n} \sum_{i=1}^{n} g_{n}(s) \text {, }
$$

where $g_{n}(s)$ is the gain from the $n$th game played.)

First, as a converse to the equivalence of $\S 2$, let $Y \subseteq X$, and denote by $Y_{n}$ the set of all members of $Y$ having rank greater than $n$. Then

$\{s: s(i) \in Y$ for infinitely many $i\}=\bigwedge_{n}\left\{s: s(i) \in Y_{n}\right.$ for some $\left.i\right\}$

$$
=\bigcap_{n} \cup\left\{\mathfrak{l l}(y) ; y \in Y_{n\}},\right.
$$


which is a $G_{\delta}$.

Now in $I$, for $t$ real, let

$$
S_{I}^{t}=\{s: h(s(i))>t \text { for infinitely many } i\},
$$

and $S_{I I}^{t}=S-S_{f}^{t}$. Then $S_{I}^{t}$ is a $G_{\delta}$, and thus the GS game

$$
\Gamma_{t}=\left(x_{0}, X_{1}, X_{1 I}, X, f, S, S_{l}^{t}, S_{l I}^{t}\right)
$$

is strictly determined. Let

$$
v=\sup \left\{t: \sum_{T}^{W}\left(\Gamma_{t}\right) \Lambda\right\} .
$$

Since $S_{I}^{K}=\Lambda, S_{I}^{-K}=S$, and $S_{I}^{t}$ is a decreasing function of $t$, we have

$$
-K \leqslant v \leqslant K, \quad \sum_{I}^{W}\left(\Gamma_{t}\right) \neq 1 \quad \text { if } t<v,
$$

and

$$
\sum_{I I}^{W}\left(\Gamma_{t}\right) \rightleftharpoons \Lambda \text { if } t>v .
$$

Given $\varepsilon>0$, choose

$$
\sigma_{0} \in \sum_{I}^{W}\left(\Gamma_{v-\varepsilon}\right) \text { and } \tau_{0} \in \sum_{I I}^{W}\left(\Gamma_{v+\varepsilon}\right) .
$$

Then for any

$$
\sigma \in \sum_{I}(\Gamma), \quad \tau \in \sum_{I I}(\Gamma)
$$

we have

$$
\left.h\left(\left\langle\sigma_{0}, \tau\right\rangle(i)\right)\right\rangle v-\varepsilon \text { for infinitely many } i
$$

and do not have

$$
\left.h\left(\left\langle\sigma, \tau_{0}\right\rangle(i)\right)\right\rangle v+\varepsilon \text { for infinitely many } i ;
$$

so that

$$
\Phi\left(\left\langle\sigma_{0}, \tau\right\rangle\right) \geqslant v-\varepsilon \text { and } \Phi\left(\left\langle\sigma, \tau_{0}\right\rangle\right)<v+2 \varepsilon \text {. }
$$

Hence

$$
v-\varepsilon \leqslant \sup _{\sigma} \inf _{\tau} \Phi(\langle\sigma, \tau\rangle) \leqslant \inf _{\tau} \sup _{\sigma} \Phi(\langle\sigma, \tau\rangle) \leqslant v+2 \varepsilon ;
$$

thus $I^{r}$ is strictly determined, and has value $v$.

\section{REFERENCES}

1. David Gale and F. M. Stewart, Infinite Games with Perfect Information. Ann. of Math. Studies 28 (Contributions to the Theory of Games II), 245-266. Princeton, 1953.

2. Dean Gillette, Representable Infinite Games. Thesis, University of California, Berkeley, June 1953.

3. H. W. Kuhn, Extensive Games and the Problem of Information. Ann. of Math. Studies 28, 193-216.

4. Philip Wolfe, Games of Infinite Length. Thesis, University of California (1954). 



\section{PACIFIC JOURNAL OF MATHEMATICS}

\section{EDITORS}

\author{
H. L. Royden \\ Stanford University \\ Stanford, California \\ E. Hewite \\ University of Washington \\ Seattle 5 , Washington
}

\author{
R. P. Dilworth
}

California Institute of Technology Pasadena 4, California

\section{A. HorN*}

University of California

Los Angeles 24, California

\section{ASSOCIATE EDITORS}

\author{
H. BUSEMANN \\ HERBERT FEDERER \\ MARSHALL HALL
}

\author{
P. R. HALMOS \\ HEINZ HOPF \\ ALFRED HORN
}

\author{
R. D. JAMES \\ BORGE JESSEN \\ PAUL LÉVY
}

GEORGE PÓLYA

J. J. STOKER

KOSAKU YOSIDA

\section{SPONSORS}

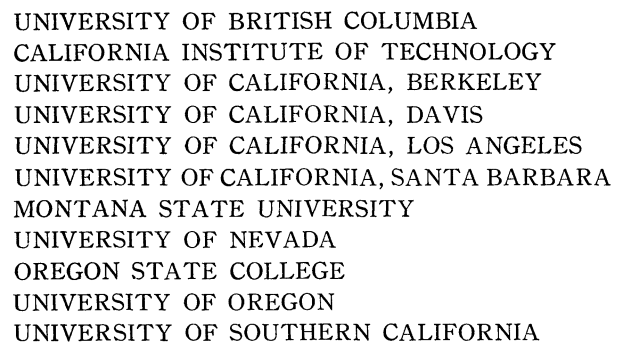

UNIVERSITY OF BRITISH COLUMBIA

CALIFORNIA INSTITUTE OF TECHNOLOGY

UNIVERSITY OF CALIFORNIA, BERKELEY

UNIVERSITY OF CALIFORNIA, DAVIS

UNIVERSITY OF CALIFORNIA, LOS ANGELES

UNIVERSITY OF CALIFORNIA, SANTA BARBARA

MONTANA STATE UNIVERSITY

UNIVERSITY OF NEVADA

OREGON STATE COLLEGE

UNIVERSITY OF OREGON

UNIVERSITY OF SOUTHERN CALIFORNIA

\author{
STANFORD RESEARCH INSTITUTE \\ STANFORD UNIVERSITY \\ UNIVERSITY OF UTAH \\ WASHINGTON STATE COLLEGE \\ UNIVERSITY OF WASHINGTON
}

AMERICAN MATHEMATICAL SOCIETY

HUGHES AIRCRAFT COMPANY SHELL DEVELOPMENT COMPANY

Mathematical papers intended for publication in the Pacific Journal of Mathematics should be typewritten (double spaced), and the author should keep a complete copy. Manuscripts may be sent to any of the editors. Manuscripts intended for the outgoing editors should be sent to their successors. All other communications to the editors should be addressed to the managing editor, Alfred Horn at the University of California Los Angeles 24, California.

50 reprints of each article are furnished free of charge; additional copies may be obtained at cost in multiples of 50 .

The Pacific Journal of Mathematics is published quarterly, in March, June, September, and December. The price per volume (4 numbers) is $\$ 12.00$; single issues, $\$ 3.50$; back numbers (Volumes $1,2,3)$ are available at $\$ 2.50$ per copy. Special price to individual faculty members of supporting institutions and to individual members of the American Mathematical Society: $\$ 4.00$ per volume; single issues, $\$ 1.25$.

Subscriptions, orders for back numbers, and changes of address should be sent to the publishers, University of California Press, Berkeley 4, California.

Printed at Kokusai Bunken Insatsusha (International Academic Printing Co., Ltd.) No. 10 1-chome Fujimi-cho, Chiyoda-ku, Tokyo, Japan.

* During the absence of E. G. Straus. 


\section{Pacific Journal of Mathematics}

\section{Vol. 5, No. $5 \quad$ BadMonth, 1955}

Henry A. Antosiewicz, A theorem on alternatives for pairs of matrice . . . . . 641

F. V. Atkinson, On second-order non-linear oscillation ............... 643

Frank Herbert Brownell, III, Fourier analysis and differentiation over real separable Hilbert spac .................................. 649

Richard Eliot Chamberlin, Remark on the averages of real function ...... 663

Philip J. Davis, On a problem in the theory of mechanical quadrature ... . . 669

Douglas Derry, On closed differentiable curves of order $n$ in $n$-spac ...... 675

Edwin E. Floyd, Boolean algebras with pathological order topologie ... . . 687

George E. Forsythe, Asymptotic lower bounds for the fundamental frequency of convex membrane ................................. 691

Israel Halperin, On the Darboux propert ................... 703

Theodore Edward Harris, On chains of infinite orde .............. 707

Peter K. Henrici, On certain series expansions involving Whittaker functions

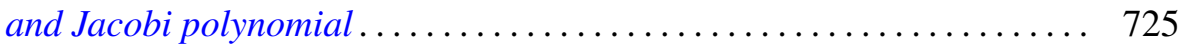

John G. Herriot, The solution of Cauchy's problem for a third-order linear hyperoblic differential equation by means of Riesz integral ......... 745

Jack Indritz, Applications of the Rayleigh Ritz method to variational

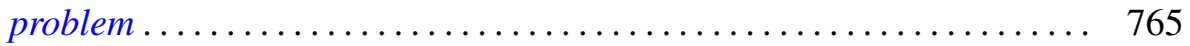

E. E. Jones, The flexure of a non-uniform bea ................. 799

Hukukane Nikaidô and Kazuo Isoda, Note on non-cooperative convex game.

Raymond Moos Redheffer and W. Wasow, On the convergence of asymptotic solutions of linear differential equation . . .

S. E. Warschawski, On a theorem of L. Lichtenstei ...........

Philip Wolfe, The strict determinateness of certain infinite game... 